\title{
A social network analysis: identifying influencers in the COVID-19 vaccination discussion on twitter
}

\author{
Muhammad Habibi, ${ }^{1, *}$, Puji Winar Cahyo \\ Department of Informatics, Universitas Jenderal Achmad Yani Yogyakarta, Indonesia
}

\begin{tabular}{l}
\hline Article Info \\
\hline Article history: \\
Received September 8, 2021 \\
Accepted November 22, 2021 \\
Published November 30, 2021
\end{tabular}

Keywords:

Socia lnetwork a naly sis

Socialmedia a nalytics

Data mining

Socialmedia

Twitter

\begin{abstract}
Social media analytics, especially Twitter, has experienced significant growth over the last few years. The data generated by Twitter provides valuable information to many stakeholders. The presence of influ en cers on social media can invite interaction with other users. An Influencer has the opportunity to create and spread hoax news related to COVID-19 vaccination intentionally or unintentionally that can harm society. This study finds out the influence of influencers and information dissemination channels on Twitter data related to COVID-19 vaccination in Indonesia as one of the hot Twitter discussion trends. This study applies Social Network Analysis (SNA) to show that interactions between users have differences when the an aly zed tweets are divided into mention and retweet networks. This study found th at the key accounts in disseminating information related to COVID-19 vaccination were dominated by official accounts of government organizations and online news portals. The result of this study can be used as a reference that government policies will be more effective in dissemin ating information if official government agency accounts carry it out. The of ficial account minimizes incorrect information appearing in the community and can control the flow of information dissemination if the information s pread has negative sentiments.
\end{abstract}

\section{Corresponding Author:}

Muhammad Habibi,

Department of Informatics,

Universita s Jenderal Achmad Ya ni Yogyakarta,

Jl. Siliwa ngi, Ringroad Barat, Banyuraden, Ga mping, Sleman, Daerah Istimewa Yogyakarta.

Email: *muhammadhabibi17@gmail.com

\section{INTRODUCTION}

The massive use of social media by the community today makes the dissemination of in formation very fast. Twitter is one of the most popular social media platforms among internet use rs to day. B ased on data from katadata, the active Twitter users in Indonesia are 14.05 million in 2021 [1]. The data generated by social media such a s Twitter provides valuable information to many stakeholders rega rding users' be hav ior, preferences, tastes, and characteristics. This information can be used as a reference in policy-making, for exa mple, to develop a marketing strategy for the company.

In certain situations, social media supports users to obtain and share fake news or hoaxes. Hoax news is untrue information that is made a $\mathrm{s}$ if it is proper to mislead the public. News related to the COVID-19 vaccination in Indonesia is one of the headlines containing many hoaxes. A person or grou p of people can carry out the spread of hoax news to incite or disturb the pu blic. Accounts that actively share informatio $n$ on socialmedia are usually called influencer accounts. The presence of influencers on social media ca $\mathrm{n}$ in vite interaction with other u sers. An Influencer can create and spread hoax news related to COVID-19 vaccination intentionally or unintentionally, which can negatively impact society.

Twitter users build their network of friends and widely share, discover, and disseminate information. Twitter provides various features for interacting, such as tweeting, following, replying, retweeting, and liking. They can see the dissemination of information on socialmedia by using Social Network An aly sis (SNA). SNA is the prim ary a nalytical tool that aims to connect existing connections between users to rev eal 
the type and nature of interactions within and between groups and individuals [2]. Twitter users are a social network that forms a graph where each usercan be a point and a relationship between other users [3].

Social Network Analysis (SNA) studies patterns of social relationships that comprise social structures, treating these relationships as a network of connections between individuals and groups that en ter into it. Specific individuals can form this rela tionship; social network analysis is not limited to mic ro-level interactions [4]. Central actors or highly connected people in a socialnet work have more power than people who are less connected [5], [6]. Main actors have early access to information; they can promote any product, sprea d opinions or movements, predict business outcomes of a network, and so on. Thus, thesecentral actors can play essential roles in fina nce and business [7], viral marketing [8], the spread of disease [9]-[11], and so on.

Socialmedia data provides the meaning to perform various kinds of analysis. The analy sis related to SocialNetwork Analysis (SNA) wa s used to see social behavior and interactions that occuron social m edia users, especially Twitter [12] [14], and to block malicious comments by revealing the main perpetrators [15]. Another study used Social Network Analy sis (SNA) wa s to determine the rela tionship between influencers and users regarding disseminating information on a cosmetic brand on Twitter [16]. Visiting tourist a rriv als [17], it is related to COVID-19 pandemic data to characterize activities and characteristics of online communities [18] and to analyze hashtags [19]. Social Network Analysis (SNA) was used to find crim inal actors/behaviors [20]-[22]. In addition, it is also used in the literacy field to help display the rela tionship between authors from the libraries used [23], [24].

This study aims to create an analy tical tool used to see the influence and distribu tion channels of information related to COVID-19 vaccination in Indonesia on Twitter. The Social Network Analysis (SNA) method was used to know thepath of information dissemination on socialmedia to see news so urces and users who influence the spread. This study visualized the dissemination of information into a social net work and introduce actors who have a high number of interactions in the social network [12]. SNA has the a dvantage of theoretical concepts, methods, and a nalytical techniques to reveal the socialrelation ships that individuals and groups have together, the structure of these relationships, and how these rela tionships and influence by social behavior, a ttitudes, beliefs, and knowledge [25]. This pa per applies SNA as a theoretical and methodological framework to show the interactions between users differ when the entire network is analyzed and divided into mention and retweet networks [26], [27]. There is a $\mathrm{n}$ a pparent ga $\mathrm{p}$ from the research conducted with previous research, namely that we divide the tweet social network into two networks, namely themention and retweet network. In addition, we a lso perform a more in-depth analysis of the two networks. Retweet networks can be a measure of how much attention ret weet users are attracted through their posts. The extent to which he provoked a reaction is in the generaldiscussion. The Mention Network points to some users who may be interested or used to prove a point.

\section{RESEARCHMETHOD}

The a naly sis process of Social Network Analysis in this research consists of three stages. They a re data extraction and preprocessing, building a network model, and measuring centrality value.

\subsection{Data Extraction and Preprocessing}

This study implements a web scraping technique to extract tweet data related to COVID-19 vaccination from web-based Twitter. Online data extraction refers to the routin e extraction of $d$ ata from expandable web data sources [28]. After thetweet data is collected, the next step is preprocessing. In th is step, we filter tweets that a re retweets and take the username or a ctor da ta mentioned in each tweet data.

\subsection{Network Model}

The second stage of this research is to build a network model. In the network model, Twitter u sers a re represented a nodes, and their connections are represented as edges. When a user publishes a tweet and mentions a nother user, a link occurs; or by using the retweet path when a tweet is retweeted or shared by other users. Figure 1 shows a network model representation of this case. 


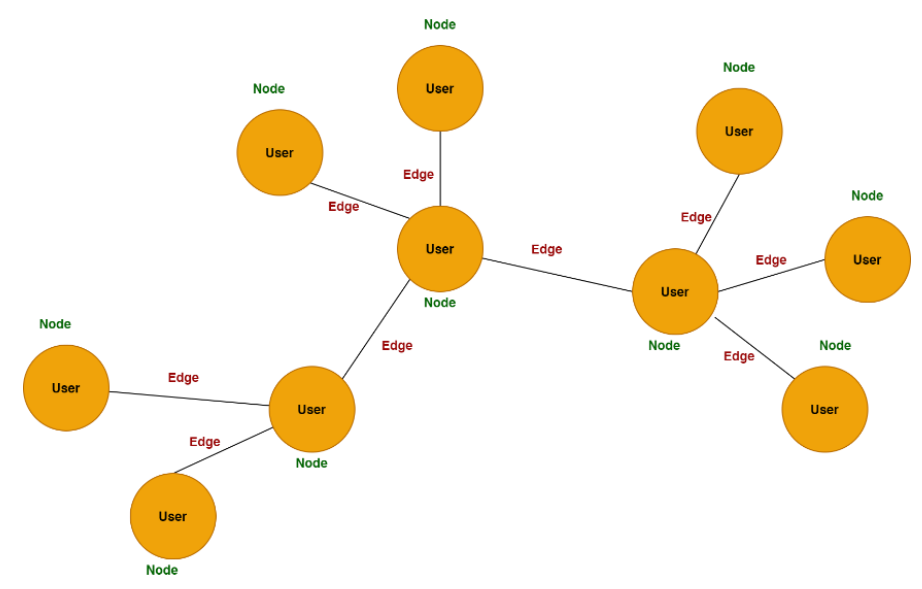

\subsection{Centrality Measure}

Figure 1. The network model representation

The measure of centrality is one of the most widely used indicators based on network data. They generally reflect the advantages of the unit; in different substantive settings, this may be its structural strength, status, prestige, or visibility. The studies of it often use network-based measures of centrality to expla in differences between units in behavior or a ttitudes [29]. This study u ses four centrality measurements, such as degree, betweenness, closeness, and eigenvector centrality, to analyze COVID-19 Vaccination Tweets in Indonesia. We use the fourcentrality measurements based on the importance of e ach centrality mea surements. Degree centrality and closeness centrality indicate reachability, and this ca tegory means whether two a ctors (nodes) are connected directly or indirectly by any path. Betweenness centrality sugge st s the shortest route. There are different paths between two nodes in the network. The centrality measure of this category is used to find the fastest way from the source (start point) to the sinking point (endpoint). Eigenvector centrality shows feedback. A node will be necessary if its neighbors are essential. The size of the centra lity of a node depends on the size of all nodes [30], [31].

\subsubsection{Degree Centrality}

Degree Centra lity is a simple count of the totalnumber of connections connected to a node. It can be considered a popularity measure but a rough measure that does not recognize the difference between quantity and quality [32]. We used degree centrality to identify the most connected users in a tweet that can be measured using equation (1),

$$
C_{D}(i)=\sum \frac{d_{1}}{n-1}
$$

where user represents as $i$ and total nodes (users) in the network represent as $n$.

\subsubsection{Betweenness Centrality}

Betweenness centrality is to measure therole of a nodeas a mediator in the network. We use this centra lity to show how significant a user is to act as a bridge in the network, which can be measured u sing equation (2). In this ca se, the users represent as $i$, the number of shortest paths from actor $j$ to actor $k$ shown a s $g_{i, k}$, and the number of shortest paths from actor $j$ to a ctor $k$ through a ctor $i$ shown as $g_{i, k}(i)$.

$$
C_{B}(i)=\Sigma \frac{g_{j, k}(i)}{g_{j, k}}
$$

\subsubsection{Closeness Centrality}

Closeness centrality measures the distance from one node to another by measuring the a verage length of other nodes in the network [33]. We use this centrality to show the closeness of the connection between users, which can be measured using equation (3). $C_{c}(i)$ is the closeness centrality of node $i$, a nd $D_{i j}$ is the shortest path from node $i$ to node $j$.

$$
C_{c}(i)=\frac{n-1}{\sum D_{i j}}
$$

\subsubsection{Eigenvector Centrality}

The eigenvector centrality measures the number of connections of a given node and its relevance in information movement [34]. We used eigenvector centrality to show the importance of users based on their 
link, which can be measured using equation(4). The users represent as $i$, constant represents as $\lambda$, a nd $a_{i, j}$ is shown adjacency matrix of the network.

$$
c_{i}(i)=\frac{1}{\lambda} \sum_{j \in G} a_{i j j}
$$

\section{RESULTS AND ANAL YSIS}

In this section, we discuss the results of the calculations we have done. For the first time, we performed data profiling from data extraction. After that, we found users who had an essential role in disseminating information regarding the COVID-19 Va ccination on Twitter using SNA.

\subsection{Data Profiling}

We ha ve collected 8,279 public tweets from Twitter based on the keywords \#VaccinationNational or \#va ccinationnasional. Tweet data was taken from March 27 to July 11,2021, which is aboutfour months. We chose these months because period 2 of the COVID-19 vaccination in Indonesia began in early April 2021 to reach a population of up to 181.5 million people [35]. During this period, there were many public pro and con tweets rela ted to the COVID-19 vaccination program.

\subsection{Centrality Measure}

The study identified three types of interactions between accounts, namely m ention, re ply, a nd retweet. Any tweet that has no mention is considered the original or original message but it does not interact. However, they can be retweeted or replied to. Among the 8279 downloaded tweets, 4795 were retweets, a nd 3474 were original tweets.

After that, the tweets were classified into two major groups. Mentions and replies are the first groups. We included "reply" in the first group because when a user gives a "reply" to a nother user, the messa ge is codified by mentioning the a ccount that was given a "reply". The second group is retweets given to messages posted by other users. We included retweets in the second groupbecause retweets are the most effective way to spread the original messa ge to indirect links [36]. Retweets a re an essential metric for understanding specific uses of Twitter [37]. The process of distinguishing between mentions and ret weets is in line with other a uthors [38]. But it is rarely used in the literature. This a pproach allows us to discover hidden interaction patterns that would be difficult to notice in a complete network.

Ba sed on 8,279 tweet data, 1643 nodes were obtained, with 5175 edges for tweets in the mentio ned category. As for the retweet category tweets, 1568 nodes were received, with a total of 4772 edges. We will discuss the centrality measure; the calculated centrality measures include degree, betweenness, closeness, and eigenvector centrality. Degree Centrality is a simple measure of centrality that counts how many connections or neighbors a node has. Users who have the highest number of neighbors can be seen in Table 1 .

\begin{tabular}{|c|c|c|c|c|c|}
\hline \multicolumn{6}{|c|}{ Mention } \\
\hline No & User & Degree Centrality & No & User & Degree Centrality \\
\hline 1 & @KemenkesRI & 780 & 1 & @ KemenkesRI & 769 \\
\hline 2 & @ sikecilmarmut & 174 & 2 & @sikecilmarmut & 147 \\
\hline 3 & @Puspen_TNI & 84 & 3 & @Puspen_TNI & 84 \\
\hline 4 & @ deen_hotfm & 81 & 4 & @ deen_hotfm & 81 \\
\hline 5 & @TjahjantoHadi & 54 & 5 & $@$ SinarOnline & 45 \\
\hline 6 & @SinarOnline & 45 & 6 & @ zunarkartunis & 37 \\
\hline 7 & @ zunarkartunis & 37 & 7 & @GajahHardhoni & 25 \\
\hline 8 & @MndJaya & 31 & 8 & @RameshRaoAKS & 20 \\
\hline 9 & @Zaindamai & 26 & 9 & @pnugroho28 & 17 \\
\hline 10 & @GajahHardhoni & 25 & 10 & @dink2525 & 17 \\
\hline
\end{tabular}

Ba sed on Table 1, it is known that ten actors or users a re active in disseminating information related to COVID-19 vaccination. These ten users a re essential because they have the highest number of connections to other users. The ten users with the highest degree of centrality have differences between mention and retweet groups. We can see that the ten u sers with thehighest Degree cent rality value for the mentioned group are@KemenkesRI, @ sismallmarmut, @Puspen_TNI, @deen_hotfm, @TjahjantoHadi, @SinarOnline, @zunarkartunis, @MndJaya, @Zainpeace, and @GajahHardhoni. As for the retweet, the group is @KemenkesRI, @sismallmarmut, @Puspen_TNI, @deen_hotfm, @SinarOnline@zunarkartunis, @GajahHardhoni, @RameshRaoAKS, @pnugroho28, and @dink2525.

The following discussion is about Closeness Centrality. Closeness Centrality shows how close the user is to all otherusers on the network. Closeness Centrality data of users can be seen in Ta ble 2 . In the mentioned group, ten users who have themost closeness with all users in the network a re @ KemenkesRI, @ sismallmarmut, @Corona_SSYT, @CaronaUpdates, @CahyoKlaten,@Puspen_TNI, @ TjahjantoHadi, 
@SinarOnline, @deen_hotfm, and @dink2525. Meanwhile, the retweet group is@KemenkesRI, @ sismallmarmut, @Corona_SSYT, @lignummare, @CaronaUpdates, @CahyoKlaten, @Puspen_TNI, @SinarOnline, @deen_hotfm, and @dink2525.These userscan be used to get the maximum speed of information flow rela ted to COVID-19 vaccination data.

Table 2. Closeness Centrality

\begin{tabular}{|c|c|c|c|c|c|}
\hline \multicolumn{3}{|c|}{ Mention } & \multicolumn{3}{|c|}{ Retweet } \\
\hline No & User & Closeness Centrality & No & User & Closeness Centrality \\
\hline 1 & @ KemenkesRI & 0,4789 & 1 & @ KemenkesRI & 0,4830 \\
\hline 2 & @ sikecilmarmut & 0,3460 & 2 & @ sikecilmarmut & 0,3413 \\
\hline 3 & @Corona_SSYT & 0,3254 & 3 & @Corona_SSYT & 0,3250 \\
\hline 4 & @CaronaUpdates & 0,3152 & 4 & @lignummare & 0,3199 \\
\hline 5 & @CahyoKlaten & 0,3040 & 5 & @CaronaUpdates & 0,3162 \\
\hline 6 & @Puspen_TNI & 0,2442 & 6 & @CahyoKlaten & 0,3039 \\
\hline 7 & @TjahjantoHadi & 0,2384 & 7 & @Puspen_TNI & 0,2438 \\
\hline 8 & @SinarOnline & 0,2380 & 8 & @SinarOnline & 0,2361 \\
\hline 9 & @ deen_hotfm & 0,2346 & 9 & @deen_hotfm & 0,2347 \\
\hline 10 & @ dink2525 & 0,2226 & 10 & @ dink2525 & 0,2216 \\
\hline
\end{tabular}

Betweenness Centrality indicates how often other nodes pass through a node to get to a specific node in the network. This value serves to determine the role of the user a s a bridge for in teraction in the network. User da ta that has the highest betweenness centrality value can be seen in Table 3 . The ten users with the highest betweenness centrality value for the mentioned group a re @ KemenkesRI, @ sismallmarmut, @CaronaUpdates, @deen_hotfm, @Corona_SSYT, @Puspen_TNI, @SinarOnline, @TjahjantoHadi, $@$ CahyoKlaten, and @ dink2525. At the same time, the ten users for the retweet group are @ Ke menkesRI, @ sismallmarmut, @CaronaUpdates, @deen_hotfm, @Puspen_TNI, @Corona_SSYT, @SinarOnline, @CahyoKlaten, @dink2525, and @lignummare. These users are located in the communic ation channel a nd can control the flow of information regarding COVID-19 Vaccination data on Twitter.

Table 3. Betweenness Centrality

\begin{tabular}{clc|clc}
\hline \multicolumn{2}{c|}{ Mention } & \multicolumn{3}{c}{ Retweet } \\
\hline No & User & Betweenness Centrality & No & User & Betweenness Centrality \\
\hline 1 & @KemenkesRI & 0,6083 & 1 & @KemenkesRI & 0,5986 \\
2 & @sikecilmarmut & 0,1683 & 2 & @ sikecilmarmut & 0,1727 \\
3 & @CaronaUpdates & 0,0766 & 3 & @CaronaUpdates & 0,0785 \\
4 & @deen_hotfm & 0,0762 & 4 & @deen_hotfm & 0,0783 \\
5 & @Corona_SSYT & 0,0567 & 5 & @Puspen_TNI & 0,0758 \\
6 & @Puspen_TNI & 0,0537 & 6 & @Corona_SSYT & 0,0499 \\
7 & @SinarOnline & 0,0521 & 7 & @SinarOnline & 0,0450 \\
8 & @TjahjantoHadi & 0,0212 & 8 & @CahyoKlaten & 0,0199 \\
9 & @CahyoKlaten & 0,0203 & 9 & @dink2525 & 0,0191 \\
10 & @dink2525 & 0,0195 & 10 & @lignummare & 0,0160 \\
\hline
\end{tabular}

Eigenvector Centrality is used to measure the importance of a node by considering the interests of its neighbors. User da ta with the highesteigenvector centrality can be seen in Table 4 . The ten hashtags for mentiongroups are @ KemenkesRI, @ sismallmarmut, @Corona_SSYT, @CaronaUpdates, @CahyoKlaten, @Puspen_TNI, @TjahjantoHadi, @SinarOnline, @deen_hotfm, and @dink2525. At the same time, the ten users for the retweet group are@KemenkesRI, @sismallmarmut, @lignummare, @Corona_SSYT, @CaronaUpdates, @CahyoKlaten, @Puspen_TNI, @deen_hotfm, @SinarOnline, and @dink2525.

Table 4. Eigenvector Centrality

\begin{tabular}{|c|c|c|c|c|c|}
\hline \multicolumn{3}{|c|}{ Mention } & \multicolumn{3}{|c|}{ Retweet } \\
\hline No & User & Eigenvector Centrality & No & User & Eigenvector Centrality \\
\hline 1 & @KemenkesRI & 0,7060 & 1 & @KemenkesRI & 0,7067 \\
\hline 2 & @ sikecilmarmut & 0,0392 & 2 & @ sikecilmarmut & 0,0327 \\
\hline 3 & @Corona_SSYT & 0,0262 & 3 & @lignummare & 0,0261 \\
\hline 4 & @CaronaUpdates & 0,0253 & 4 & @Corona_SSYT & 0,0260 \\
\hline 5 & @CahyoKlaten & 0,0253 & 5 & @CaronaUpdates & 0,0256 \\
\hline 6 & @Puspen_TNI & 0,0130 & 6 & @CahyoKlaten & 0,0255 \\
\hline 7 & @TjahjantoHadi & 0,0107 & 7 & @Puspen_TNI & 0,0124 \\
\hline 8 & @SinarOnline & 0,0010 & 8 & @deen_hotfm & 0,0010 \\
\hline 9 & @ deen_hotfm & 0,0010 & 9 & @SinarOnline & 0,0010 \\
\hline 10 & @ dink2525 & 0,0009 & 10 & @ dink2525 & 0,0009 \\
\hline
\end{tabular}


Based on the values of degree centrality, closeness centrality, betweenness centrality, and eigenvector centrality, we manually check their profiles and cla ssify them for more in formation on u ser a ccounts with high scores. It was found that the accounts were primarily official a ccounts of government organization, online news portals, personal accounts, and some were un verif ied a ccoun ts because their contents were only retweeted with specific hashtags. Accounts that a re official government accounts that a re active in disseminating vaccination information a re the @ KemenkesRI and @ Puspen_TNI accounts, and the @ KemenkesRI account is the official Twitter a ccount from the Ministry of Health of the Republic of Indonesia, while the @Puspen_TNI a ccount is the official Twitter account from the TNI Information Center. Accounts which are online news portal accounts are@SinarOnline, @ Corona_SSYT, @CaronaUpdates. The official Twitter account of government organizations turned out to have an essential role in disseminating information related to COVID-19 vaccination, namely the official a ccount of the Min istry of Health and the TNI Information Center.

The mentioned network is built by observing when a user mentions another user. The link direction goes to the mentioned u ser. They were a directed network, which reveals the in-degree versu s o ut-degree sta tistics of the network. Mention networks provide clues about who may have more significant influence. The a nalysis carried out shows that 1643 nodes are participating in the mention network with 5175 edges, which can be seen in Figure 2.

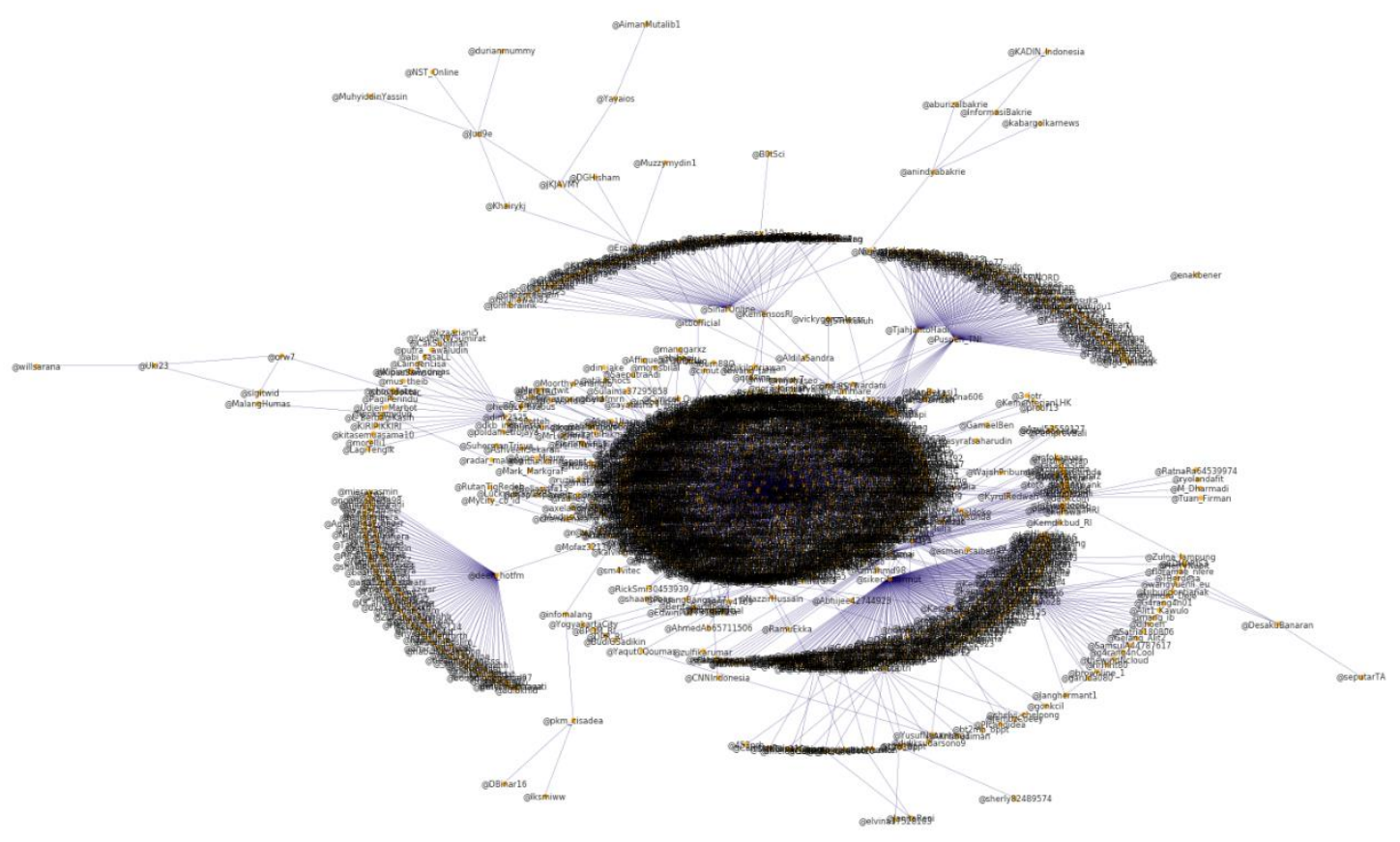

Figure 2. Mention Network

The retweet network is a directional and weighted graph where nodes represent Twitter users, while edges a re formed each time a retweet occurs. The direction of the link mirrors the retweet mechan is m, with the path pointing to the user being retweeted. Figure 3 illustrates this network. B efore build ing a retweet network, the number of followers is used to determine the importance of nodes. The analy sis shows that 1568 nodes are participating in the retweet network with 4772 edges.

The results of our study show that strong and weak bonds a re essential to forming a network - the two mix in the network dynamics on Twitter. The first is to expand the web, and the second is to stren gthen it. Through weak ties, its users enter new information and content, part of their network, in to the lea ding network. After that, through a strong bond, users increase the flow of information and spread it in the network. Then the data can be picked up by other users and spread to outside networks. Thus, this three-stage process (inserting-streaming-spreading) is related to the importance of retweets because retweets are the most effective way to spread messages [36]. But it should also be emphasized that this information dissemination process can be triggered by mentions or a combination of retweets and mentions. 


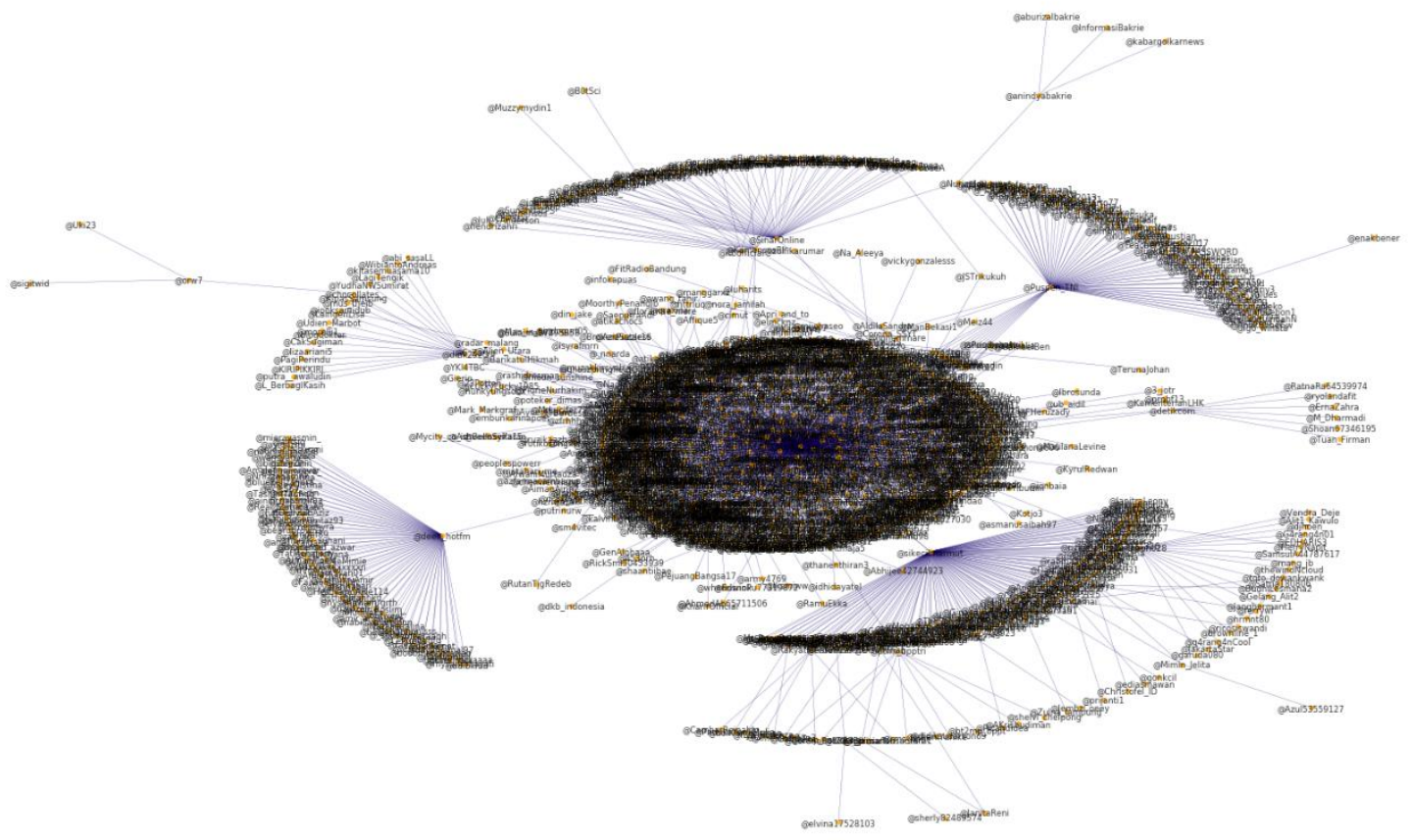

Figure 3. Retweet Network

Social Network Analy sis is used to determine the effect of hashtags related to COVID-19 tweet data on socialmedia as in the study [39], but without paying attention on the tweet mentions and tweet ret weets. Based on the results of this study, we can see that Social Network Analysis related to COVID-19 data by dividing socialnetworks into mention networks and retweet networks has more in-depth discussion a nalys is . The use of mention network and retweet network is because the interaction pattern be tween mentions and retweets ha s differences in the dissemination of information. In a ddition, the Social Network Analysis related to the COVID-19 vaccination that has been produced in this study can be used as a reference that government policies will be more effective in disseminating information if official government agency account $\mathrm{s}$ arry it out. The official a ccount minimizes the presence of incorrect information appearing in the community. In a ddition, the official a ccount can also control the flow of information dissemination if the information spread has negative sentiments.

\section{CONCLUSION}

This study analyzes a dataset of tweets discussing topics related to COVID-19 vaccination in Indonesia. Our research offers a new perspective to explore users' characteristics and roles in a net work on socialmedia Twitter. Using the Social Network Analy sis indicator shows that interaction s betw een users differ when theentire network is analyzed and divided into mention and retweet networks. By perf orming this ana lysis, hidden interaction patterns are revealed. This viewpoint allows identifying the u ser fu nctions involved in the network. In addition, this research provides new insights into how the Twitter net work is formed and how it can be understood. This research contributes by showing how SNA identifies key actors on Twitter socialmedia with a particular topic. This study found that the key a ccounts in disseminating information related to Covid-19 vaccination were dominated by official accounts of government organizations a nd online news portals. The result of this study can be used as a reference that go vernment policies will be more effective in disseminating information if official government agency account s carry it out. The official a ccount minimizes the presence of incorrect information appearing in the community. In a ddition, the official a ccount can a lso control the flow of information dissemination if the information spread has negative sentiments.

\section{ACKNOWLEDGEMENTS}

This research wa s conducted in 2021 of Penelitian Dosen Pemula (PDP) scheme funded by the Ministry of Education, Culture, Research and Technology of the Republic of Indonesia. There se arch tea $\mathrm{m}$ would like to thank the Ministry of Education, Culture, Research and Technology for allowing the re search tea $\mathrm{m}$ to add insight and knowledge through research in this scheme. The data supported by Center of Study and Data Analytic Services of Universitas Jenderal Achmad Yani Yogyakarta. Hopefully, this re search can bring benefits to the progress of the Indonesian nation. 


\section{REFERENCES}

[1] M. A. Rizaty, "Siapa Tokoh Terpopuler di Twitter pada 2021?," katadata.co.id, 09-Jul-2021. [Online]. Available: https://databoks.katadata.co.id/datapublish/2021/07/09/siapa-tokoh-terpopuler-di-twitter-pada-2021. [Accessed: 05-Sep-2021].

[2] M. Steketee, A. Miyaoka, and M. Spiegelman, "Social Network Analysis," in International Encyclopedia of the Social \& Behavioral Sciences: Second Edition, Elsevier Inc., 2015,pp. 461-467.

[3] J. A. Ginting, D. Manongga, and I. Sembiring, "The spread path of hoax news in social media (facebook) u sing social network analysis (SNA)," in 2018 International Seminar on Research of Information Technology and Intelligent Systems (ISRITI), 2018, pp. 405-409.

[4] J. Scott and F. N. Stokman, "Social Networks," in International Encyclopedia of the Social \& Behavioral Sciences: Second Edition, Elsevier Inc., 2015, pp. 473-477.

[5] B. A. MINTZ and M. SCHWARTZ, The Power Structure of American Business. University of Chicago Press, 1987.

[6] P. Bonacich, "Power and Centrality: A Family of Measures," Am. J. Sociol., vol. 92, no. 5, pp. 1170-1182, Mar. 1987.

[7] X. Huang, I. Vodenska, F. Wang, S. Havlin, and H. E. Stanley, "Identifying influential directors in the United States corporate governance network," Phys. Rev. E - Stat. Nonlinear, Soft Matter Phys., vol. 84, no. 4, Oct. 2011.

[8] S. P. Borgatti, “Centrality and network flow," Soc. Networks, vol. 27, no. 1, pp. 55-71, Jan. 2005.

[9] M. A. Tayebi, L. Bakker, U. Glässer, and V. Dabbaghian, "Locating central actors in co-offending networks," in Proceedings - 2011 International Conference on Advances in Social Networks Analysis and Mining, ASONAM 2011,2011, pp. 171-179.

[10] N. A. Christakis and J. H. Fowler, "Social Network Sensors for Early Detection of Contagious Outbreaks," PLoS One, vol. 5, no. 9, p. e12948, Sep. 2010.

[11] Z. W. Liang and J. P. Li, "Identifying and ranking influential spreaders in complex networks," in 201411 th International Computer Conference on Wavelet Active Media Technology and Information Processing, ICCWAMTIP 2014,2014, pp. 393-396.

[12] M. S. Setatama and D. Tricahyono, "Implementasi Social Network Analysis pada Peny ebaran Country Branding 'Wonderful Indonesia,'” Indones. J. Comput., vol. 2, no. 2, p. 91, 2017.

[13] L. Tomasoa, A. Iriani, and I. Sembiring, "Ekstraksi Knowledge tentang Penyebaran \#Ratnamiliksiapa pada Jejaring Sosial (Twitter) menggunakan Social Network Analysis (SNA),” J. Teknol. Inf. dan Ilmu Komput., vol. 6, no. 6, p. 677, 2019.

[14] W. Ignatio, M. R. D. Putra, and M. K. Bratawisnu, "Penentuan Top Brand Menggunakan Social Network Analysis pada E-Commerce Bukalapak dan Tokopedia," J. Inf. Eng. Educ. Technol., vol. 2, no. 1, pp. 1-5, 2018.

[15] Y. J. Choi, B. J. Jeon, and H. W. Kim, "Identification of key cyberbullies: A text mining and social network analysis approach,” Telemat. Informatics, p. 101504, Sep. 2020.

[16] N. M. Watanabe, J. Kim, and J. Park, "Social network analysis and domestic and international retailers: An investigation of social media networks of cosmetic brands," J. Retail. Consum. Serv., vol. 58, p. 102301, Jan. 2021.

[17] F. C. Yuan, "Intelligent forecasting of inbound tourist arrivals by social networking analysis," Phys. A Stat. Mech. its Appl., vol. 558, p. 124944, Nov. 2020.

[18] M. B. Smith, J. K. Blakemore, J. Ho, and J. A. Grifo, "MAKING IT (NET)WORK: A SOCIAL NETWORK ANALYSIS OF 'FERTILITY' ON TWITTER BEFORE AND DURING THE COVID-19 PANDEMIC,” Fertil. Steril., vol. 114, no. 3, p. e69, Sep. 2020.

[19] M. Habibi, A. Priadana, and M. R. Ma'arif, "Hashtag Analysis of Indonesian COVID-19 Tweets Using Social Network Analysis," IJCCS (Indonesian J. Comput. Cybern. Syst., vol. 15, no. 3, Jul. 2021.

[20] K. Taha and P. D. Yoo, "A system for analyzing criminal social networks," in Proceedings of the 2015 IEEE/ACM International Conference on Advances in Social Networks Analysis and Mining, ASONAM 2015, 2015, pp. 1017-1023.

[21] S. M. Alam, N. Islam, and M. S. Hosain, "Detecting most central actors of an unknown network using friendship paradox," in 2016 International Conference on Informatics and Computing, ICIC 2016, 2017, pp. 343-348.

[22] F. C. Tsai, M. C. Hsu, C. T. Chen, and D. Y. Kao, "Exploring drug-related crimes with social network analysis," in Procedia Computer Science, 2019, vol. 159, pp. 1907-1917.

[23] B. K. Wichmann and L. Kaufmann, "Social network analysis in supply chain management research," Int. J. Phys. Distrib. Logist. Manag., vol. 46, no. 8, pp. 740-762, 2016.

[24] A. Mangas-Vega, R. Gomez-Diaz, and J. A. Cordon-Garcia, "Approach to self-publishing with a combination of bibliometric study and social network analysis techniques," Electron. Libr., vol. 34, no. 6, pp. 902-914, 2016.

[25] C. Prell, Social network analysis: History, theory and methodology. London: SAGE Publications Ltd, 2012.

[26] N. Aguilar-Gallegos, L. Klerkx, L. E. Romero-García, E. G. Martínez-González, and J. Aguilar-Ávila, "Social network analysis of spreading and exchanging information on Twitter: the case of an agricultural res earch and education centre in Mexico," https://doi.org/10.1080/1389224X.2021.1915829,2021.

[27] Z. Jastania, M. A. Aslam, R. A. Abbasi, and K. Saeedi, "Using Social Network Analysis to Understand Public Discussions: The Case Study of \#SaudiWomenCanDrive on Twitter," Int. J. Adv. Comput. Sci. Appl., vol. 11, no. 2, pp. 223-231, 2020.

[28] E. Ferrara, P. De Meo, G. Fiumara, and R. Baumgartner, "Web data extraction, applications and techniques: A survey," Knowledge-Based Syst., vol. 70, pp. 301-323, Nov. 2014.

[29] P. V. Marsden, "Network Analysis," Encycl. Soc. Meas., pp. 819-825, Jan. 2005. 
[30] K. Das, S. Samanta, and M. Pal, "Study on centrality measures in social networks: a survey," Soc. Netw. Anal. Min. 2018 81, vol. 8, no. 1, pp. 1-11, Feb. 2018.

[31] N. Meghanathan, "Correlation Coefficient Analysis of Centrality Metrics for Complex Network Graphs," Adv. Intell. Syst. Comput., vol. 348, pp. 11-20, 2015.

[32] D. L. Hansen, B. Shneiderman, M. A. Smith, and I. Himelboim, "Social network analysis: Measuring, mappin g, and modeling collections of connections," Anal. Soc. Media Networks with NodeXL, pp. 31-51, Jan. 2020.

[33] M. S. Setatama and D. Tricahyono, Ir., M.M., Ph.D., "Implementasi Social Network Analysis pada Penye b ar an Country Branding 'Wonderful Indonesia,", Indones. J. Comput., vol. 2, no. 2, p. 91, Nov. 2017.

[34] C. F. A. Negre et al., "Eigenvector centrality for characterization of protein allosteric pathways," Proc. Natl. Acad.Sci. U. S. A., vol. 115, no. 52, pp.E12201-E12208, Dec. 2018.

[35] Widyawati, "Pelaksanaan Vaksinasi COVID-19 di Indonesia Membutuhkan Waktu 15 Bulan - Sehat Negeriku," Biro Komunikasi dan Pelayanan Masyarakat, 18-Jan-2021. [Online]. Available: https://sehatnegeriku.kemkes.go.id/baca/rilis-media/20210103/2536122/pelaksanaan-vaksinasi-covid-19indonesia-membutuhkan-waktu-15-bulan/. [Accessed: 05-Sep-2021].

[36] S. N. Firdaus, C. Ding, and A. Sadeghian, "Retweet: A popular information diffusion mechanism - A survey paper," Online Soc. Networks Media, vol. 6, pp. 26-40, Jun. 2018.

[37] K. Weller, "Trying to understand social media users and usage: The forgotten features of social media platforms," Online Inf. Rev., vol. 40, no. 2, pp. 256-264, Apr. 2016.

[38] M. Rehm and A. Notten, "Twitter as an informal learning space for teachers!? The role of social capital in Twitter conversations among teachers," Teach. Teach. Educ., vol. 60, pp. 215-223, Nov. 2016.

[39] W. Ahmed, J. Vidal-Alaball, J. Downing, and F. L. Seguí, "COVID-19 and the 5G conspiracy theory: Social network analysis of twitter data," J. Med. Internet Res., vol. 22, no. 5, p. e19458, May 2020. 
